\title{
PENGARUH CITRA RUMAH SAKIT DAN KUALITAS PELAYANAN TERHADAP LOYALITAS PASIEN MELALUI KEPUASAN PASIEN (STUDI PADA RUMAH SAKIT UMUM KARDINAH TEGAL)
}

\author{
M. Andi Ardiyanto dan Tabrani \\ RSUD Kardinah Tegal \\ Universitas Pancasakti Tegal
}

\begin{abstract}
M. Andi Ardiyanto. Influence of Image and Quality of Service To Consumer Loyalty Through Consumer Satisfaction (Study At Hospital KardinahTegal). Thesis.Tegal: Master of Management Pancasakti University of Tegal. 2017

The purpose of this research is to test empirically the influence of image and service quality to consumer loyalty through consumer satisfaction (Study AtHospital KardinahTegal). The research variables in this research are image, service quality, satisfaction and loyalty.

The hypothesis of this study is the image and quality of service influence on consumer loyalty through consumer satisfaction. Data collection method used in this research is questionnaire. While the data analysis method used is SEM analysis using AMOS application

The result of this research are (1) image have positive effect to satisfaction (2) service quality have positive effect to satisfaction (3) image have positive effect to loyalty (4) service quality have positive influence to loyalty (5) satisfaction positive effect to loyalty (6) Can mediate the influence of the image on loyalty but satisfaction can not mediate the influence of service quality on loyalty.
\end{abstract}

Keywords: Image, Service Quality, Satisfaction, Loyalty

\section{A. PENDAhULUAN}

Rumah Sakit Umum (RSU) Kardinah Tegal merupakan rumah sakit yang diselenggarakan oleh pemerintah. RSU Kardinah bermula dari balai pengobatan yang didirikan pada tahun 1927 oleh RA Kardinah (Istri Bupati Tegal pada masa itu). Terakhir RSU Kardinah Tegal dipimpin oleh dr. AbdaHakim. RSU Kardinah Tegal merupakan rumah sakit dengan tipe $B$ dengan berlokasi di Jl. KS. Tubun Nomor 4 Tegal.

Loyalitas konsumen telah menjadi isu menarik dalam bidang pemasaran. Penelitian empiris membuktikan bahwa kepuasan konsumen saja tidak cukup membuat konsumen loyal terhadap suatu produk (Oliver, 2009). Loyalitas konsumen ini muncul karena adanya pengaruh dari kepuasan yang dirasakan konsumen (Wijayanti, 2008). Namun, penelitian Hellier (2012) menyebutkan bahwa kepuasan konsumen dan loyalitas konsumen tidak memiliki hubungan yang signifikan. Loyalitas konsumen adalah kondisi di mana konsumen memunyai sikap positif terhadap sebuah produk, memunyai komitmen terhadap produk tersebut dan bermaksud melakukan pembelian ulang di masa yang akan datang. Seperti halnya perusahaan, RSU Kardinah juga harus 
memberikan pelayanan yang maksimal agar pasien merasa puas dan loyal terhadap RSU Kardinah. Berikut jumlah pasien RSU Kardinah dari tahun 2012 sampai 2016.

Tabel 1

Jumlah Pasien di RS Kardinah Tegal tahun 2012 sampai 2016

\begin{tabular}{|c|c|c|c|c|}
\hline No & Tahun & Pasien BPJS & Pasien Umum & Jumlah \\
\hline 1 & 2012 & 1.455 & 2.146 & 3.601 \\
\hline 2 & 2013 & 1.734 & 1.656 & 3.390 \\
\hline 3 & 2014 & 1.576 & 1.867 & 3.443 \\
\hline 4 & 2015 & 1.504 & 1.499 & 3.003 \\
\hline 5 & 2016 & 2.978 & 1.207 & 4.185 \\
\hline
\end{tabular}

Sumber : RSU Kardinah Tegal

Citra merupakan aset tidak berwujud (intangible assets) yang berharga dari perusahaan. Citra positif memungkinkan sebuah perusahaan untuk mendapatkan nilai reputasi dan keunggulan kompetitif (Porter dan Claycomb, 2007). Sebuah citra yang baik akan meningkatkan kepuasan konsumen, kualitas layanan, loyalitas, dan niat pembelian kembali (Bloemer et al., 1998;. Da Silva et.al., 2008 dan. Lai et al., 2009 dalam Hidajahningtyas, 2013:40).

Penelitian Wu (2011) menunjukkan bahwa citra rumah sakit memiliki pengaruh baik langsung maupun tidak langsung terhadap loyalitas pasien. Hal ini mengindikasikan bahwa citra rumah sakit yang baik tidak hanya meningkatkan kepuasan pasien melalui loyalitas pasien secara langsung, tetapi juga meningkatkan kepuasan pasien melalui peningkatan kualitas pelayanan yang dirasakan, yang pada gilirannya meningkatkan niat ulang kunjungan pasien. Di mana penulis akan mengacu pada penelitian yang dilakukan oleh $\mathrm{Wu}$ (2011) tentang dampak citra rumah sakit, kualitas pelayanan, kepuasan pasien dan loyalitas. Permasalahan terkait dengan citra rumah sakit dan kualitas pelayanan, juga dialami RSU Kardinah Tegal. Banyaknya pasien RSU Kardinah Tegal ini bukan berarti minim complain, hal ini diketahui setelah melakukan pengamatan langsung dengan menyurvei beberapa pasien. Hasil observasi di atas menunjukkan bahwa kualitas pelayanan RSU Kardinah Tegal perlu diperhatikan dan bahkan ditingkatkan untuk meningkatkan kualitas pelayanan yang lebih baik dari sebelumnya. Kinerja karyawan sangat berpengaruh terhadap kualitas pelayanan karena karyawan berhadapan langsung dengan konsumen. Selain itu, adanya keluhan dari konsumen yang terdapat pada layanan via sms dan saran yang telah disediakan oleh RSU Kardinah Tegal, belum semua ditanggapi secara maksimal oleh pihak RSU Kardinah Tegal, terbukti dengan masih banyaknya keluhan-keluhan yang sama tentang citra rumah sakit dan kualitas pelayanan pada RSU Kardinah Tegal. Adapun perbedaan penelitian ini dengan penelitian sebelumnya adalah penelitian ini menggunakan kepuasan sebagai variabel mediasi, subyek 
penelitian ini dilakukan di RSU Kardinah Tegal. Berdasarkan masalah tersebut, maka penulis tertarik melakukan penelitian yang berjudul "Pengaruh Citra Rumah Sakit dan Kualitas Pelayanan terhadap Loyalitas Pasien Melalui Kepuasan Pasien (Studi pada Rumah Sakit Umum Kardinah Tegal)".

\section{B. TELAAH PUSTAKA}

Loyalitas didefinisikan Oliver (dalam Goodwin, 2009:218) sebagai komitmen yang tinggi untuk membeli kembali suatu produk atau jasa yang disukai di masa mendatang, disamping pengaruh situasi dan usaha pemasar dalam merubah perilaku. Dengan kata lain konsumen akan setia untuk melakukan pembelian ulang secara terus-menerus. Hurriyati (2005:35) menyatakan bahwa loyalitas konsumen memiliki peran penting dalam sebuah perusahaan, mempertahankan mereka berarti meningkatkan kinerja keuangan dan mempertahankan kelangsungan hidup perusahaan, hal ini menjadi alasan utama bagi sebuah perusahaan untuk menarik dan mempertahankan konsumen. Usaha untuk menjadikan konsumen yang loyal tidak dapat dilakukan secara langsung, tetapi melalui beberapa tahapan, mulai dari mencari konsumen yang potensial sampai memperoleh partners.

Menurut Griffin (2013:4) "loyalty is defined as non random purchase expressed over time by some decisions making unit". Dari kalimat ini terlihatloyalitas lebih ditujukan kepada suatu perilaku yang ditujukan dengan pembelian rutin, didasarkan pada unit pengambilan keputusan. Selanjutnya Griffin (2013:13) mengemukakan keuntungan-keuntungan yang akan diperoleh perusahaan apabilamemiliki konsumen yang loyal:
1. Mengurangi biaya pemasaran (karena biaya untuk menarik konsumen baru lebih mahal)

2. Mengurangi biaya transaksi (seperti biaya negosiasi kontrak, pemrosesan pesanan dan lain-lain)

3. Mengurangi biaya turn over konsumen (karena pergantian konsumen lebih sedikit)

4. Meningkatkan penjualan silang yang akan memperbesar pangsa pasar perusahaan.

5. Word of mouth yang lebih positif, dengan asumsi bahwa konsumen yang loyal juga berarti mereka yang merasa puas.

6. Mengurangi biaya kegagalan (seperti biaya penggantian, dll).

Tjiptono (2008:24) menyatakan bahwa: "kepuasan atau ketidakpuasan konsumen adalah respon konsumen terhadap evolusi ketidaksesuaian/ diskonfirmasi yang dirasakan antara harapan sebelumnya (atau norma kinerja lainnya) dan kinerja aktual produk yang dirasakan setelah pemakaiannya".

Pengertian citra adalah apa yang dipikirkan konsumen tentang suatu produk. Termasuk didalamnya adalah persepsi dan sikap yang didasarkan pada reaksi dan rangsangan yang berkaitan dengan perusahaan yang diterima melalui kelima indera. Kotler (2007:57), "citra (image) adalah kepercayaan, ide dan impresi seseorang terhadap sesuatu". Bagi sebuah perusahaan, image atau citra yang baik mutlak diperlukan. Sedemikian penting arti dari citra (image) itu sendiri sehingga perusahaan bersedia mengeluarkan biaya dan tenaga ekstra untuk meraihnya.

Citra (image) merupakan seperangkat keyakinan, ide, dan pesan yang dimiliki seseorang terhadap suatu objek Sutisna (2001:33). Citra adalah 
tujuan utama dan sekaligus merupakan reputasi dan prestasi yang hendak dicapai public relations.

Pelayanan (service) menurut Kotler (1996) dalam (Laksana, 2008:85), yaitu: "A Service any Act or performance that party can offer to another thats isessentially intangible and does not result in the ownership of anything, itsproduction may or may no be to a physical product". Maksudnya yaitu bahwa pelayanan adalah setiap tindakan atau kegiatan yang dapat ditawarkan oleh satu pihak kepada pihak lain, yang pada dasarnya tidak berwujud dan tidak mengakibatkan kepemilikan apapun. Produksinya dapat dikaitkan atau tidak dikaitkan pada satu produk fisik. Karakteristik jasa menurut Kotler (2007:75) "Services have four major charactersistics that gretly affect the design ofmarketing programs: intangibility, inseparability, variability, and perishability".

\section{Hubungan antara citra rumah sakit dan kepuasan}

Citra (image) adalah kepercayaan, ide dan impresi seseorang terhadap sesuatu Kotler (2007:57). Citra suatu perusahaan merupakan faktor yang sering memengaruhi keputusan pembelian. Citra memengaruhi kepuasan konsumen melalui efek penyeleksian. Sementara itu, Da Silva (2003) menyatakan bahwa citra berkorelasi dengan kepuasan konsumen. Atas dasar pengalaman yang telah dimiliki konsumen (pasien), mereka akan memberikan penilaian dan evaluasi seluruh kinerja layanan rumah sakit. Penelitian $\mathrm{Wu}$ (2011) menyimpulkan bahwa citra rumah sakit yang baik tidak hanyameningkatkan kepuasan pasien melalui loyalitas pasien secara langsung, tetapi juga meningkatkan kepuasan. Berdasarkan perbandingan kualitas harapan dengan kualitas kinerja layananan, maka konsumen akan memberikan emosi positif atau emosi negatif bahkan emosi yang netral, bergantung pada apakah harapan-harapan konsumen tersebut terpenuhi. Dan dari uraian di atas maka penulis menyusun:

\section{H1 : Citra rumah sakit memberikan pengaruh terhadap kepuasan pasien.}

2. Hubungan antara kualitas pelayanan dan kepuasan

Kualitas produk baik barang maupun jasa merupakan hal penting dan yang diharapkan oleh para konsumen. Syamsiah (2011) menyebutkan bahwa keterkaitan antara kualitas layanan dengan nilai yang dirasakan adalah bahwa pelayanan yang berkualitas akan meningkatkan nilai bagi konsumen sehingga akan dapat menciptakan kepuasaan yang akhirnya dapat meningkatkan loyalitas konsumen. Penelitian lain seperti yang dilakukan oleh $\mathrm{Wu}$ (2011) menyatakan bahwa kualitas layanan yang tinggi berkorelasi dengan kepuasan konsumen yang tinggi. Kepuasan pasien berfungsi sebagai medium antara kualitas layanan dan niat perilaku. kualitas layanan kesehatan tidak hanya berkaitan dengan bagaimana layanan dari tenaga medis memberikan layanan kepada pasien namun juga bagaimana pasien merasa nyaman dengan kondisi dan situasi yang rumah sakit ciptakan. Oleh karena itu, kualitas layanan kesehatan yang dirasakan pasien diprediksi akan meningkatkan kepuasan pasien. Lestari (2014) hasil penelitiannya menunjukkan variabel citra dan kualitas pelayanan secara simultan berpengaruh positif dan signifikan terhadap kepuasan konsumen. Dalam jurnal yang disusun oleh Ariyani dan Rosinta (2010) kualitas pelayanan 
berpengaruh terhadap kepuasan kosumen, dari uraian di atas maka penulis menyusun:

\section{H2 : Kualitas pelayanan memberi- kan pengaruh terhadap kepuasan pasien.}

\section{Hubungan antara kepuasan dan loyalitas}

Syamsiah (2011) mengungkapkan bahwa manajer jasa perlu membangun peran, nilai yang dirasakan dalam menentukan kepuasan konsumen. Emosi positif yang diberikan pasien setelah menggunakan layanan kesehatan rumah sakit akan menunjukkan kepuasan mereka terhadap layanan rumah sakit. Penelitian Selnes (2003) menunjukkan bahwa kepuasan konsumen memengaruhi perilaku pembeli yang mana konsumen yang puas cenderung akan menjadi loyal. Kepuasan konsumen akan menghasilkan dampak positif bagi rumah sakit. Apabila konsumen merasa puas terhadap layanan rumah sakit, akan menciptakan penilaian bahwa rumah sakit telah mampu memberikan pelayanan maksimal kepada masyarakat.

Dalam tinjauan penelitian sebelumnya, loyalitas dapat menjadi hasil dari kepuasan konsumen Hidajahningtyas (2013). Apabila konsumen merasa puas dengan layanan rumah sakit maka akan meningkatkan kepercayaan dan keyakinan mereka bahwa rumah sakit tetap akan memberikan pelayanan yang optimal kepada pasien, sehingga konsumen akan tetap setia untuk menggunakan jasa layanan pada rumah sakit tersebut di masa yang akan datang, dan dari uraian di atas maka penulis menyusun:

\section{H3 : Kepuasan pasien memberikan pengaruh terhadap loyalitas pasien}

\section{Hubungan antara citra rumah sakit dan loyalitas}

Citra rumah sakit memiliki fungsi strategis. Citra dipandang sebagai filter yang digunakan untuk mengevaluasi kualitas keseluruhan Hidajahningtyas (2013). Darlina (2015) tentang "Pengaruh Citra Perusahaan dan Kualitas Pelayanan Terhadap Loyalitas Konsumen Pada Jasa Perhotelan" hasil analisis mengunakan regresi linear berganda, uji $t$, dan uji $f$ sehingga dapat diketahui bahwa variabel citra perusahaan berpengaruh positif terhadap loyalitas konsumen, bahwa pemberian kualitas pelayanan berpengaruh signifikan terhadap loyalitas konsumen, dan pengaruh yang signifikan antara citra perusahaan dan kualitas pelayanan terhadap loyalitas konsumen.

Dengan demikian, citra rumah sakit yang menguntungkan membantu memperkuat niat pasien untuk memilih rumah sakit. Penilaian masyarakat merupakan hal penting karena hal tersebut akan memengaruhi informasi yang beredar mengenai kinerja dan layanan yang diberikan rumah sakit. Marilees dan Fry (2012) menemukan bahwa citra memiliki efek langsung pada loyalitas. Namun demikian, citra dapat dilihat jelas sebagai penduga loyalitas konsumen. Citra yang baik akan membentuk pola pikir masyarakat bahwa apabila masyarakat memiliki kendala kesehatan, masyarakat tidak perlu berpikir dua kali kemana mereka akan mendapatkan layanan kesehatan, karena berdasarkan pengalaman yang mereka alami sendiri atau berdasarkan informasi yang mereka peroleh, 
dan dari uraian di atas maka penulis menyusun:

\section{H4 : Citra rumah sakit memberikan pengaruh terhadap loyalitas pasien}

\section{Hubungan antara kualitas pelayanan dan loyalitas}

Kualitas layanan dapat diartikan sebagai upaya pemenuhan kebutuhan dan keinginan konsumen serta ketepatan penyampainnya dalam mengimbangi harapan konsumen (Tjiptono,2004:48). Kualitas pelayanan memunyai hubungan yang erat dengan dengan loyalitas konsumen hal ini telah dikemukakan dalam penelitian Widiyawati (2013), hasil penelitian menunjukkan bahwa: faktor kualitas layanan yang meliputi faktor tangibles, reliability, responsiveness, assurance, dan empathy secara simultan berpengaruh signifikan terhadap loyalitas konsumen pada supermarket Papaya Darmo Surabaya" terbukti benar atau hipotesis tersebut diterima. Selanjutnya dalam bukunya Laksana (2008:91) menyatakan bahwa hubunganantara kualitas pelayanan dengan loyalitas ditekankan kembali oleh Hidajahningtyas (2013). Zeithaml dan Parasuraman (2000) melaporkan hubungan positif antara mutu pelayanan dan dimensi kesetiaan, yaitu kesetiaan dalam penentuan harga yang bervariasi serta kemauan membayar biaya lebih tinggi serta setia bahkan bila hargaharga naik. Oleh karena itu, kualitas pelayanan harus menjadi fokus utama perhatian perusahaan karena dapat menciptakan loyalitas, dari uraian di atas maka penulis menyusun:

\section{H5: Kualitas pelayanan memberi- kan pengaruh terhadap loyalitas pasien.}

6. Hubungan antara citra rumah sakit, dan kualitas pelayanan terhadap loyalitas melalui kepuasan

Citra perusahaan yang baik tentu saja akan berpengaruh baik terhadap persepsi konsumen. Begitu juga kualitas pelayanan yang baik juga akan berdampak positif terhadap perusahaan. Dua faktor ini akan berdampak positif terhadap kepuasaan dan loyalitas konsumen. Dalam penelitian Margita (2016) menjelaskan bahwa citra rumah sakit berpengaruh signifikan terhadap kepuasan, kualitas layanan berpengaruh signifikan terhadap kepuasan, serta variabel kepuasan berpengaruh signifikan terhadap loyalitas. Begitu juga penelitian Prahastuti (2011) variabel citra, kualitas pelayanan dan kepuasan berpengaruh signifikan terhadap loyalitas. Dari uraian tersebut maka penulis menyusun:

\section{H6 : citra rumah sakit dan kualitas pelayanan memberikan pengaruh terhadap loyalitas melalui kepuasan pasien}

\section{METODE PENELITIAN}

Jenis penelitian ini termasuk jenis penelitian survei. Peneliti menggunakan jenis penelitian survei karena penelitian yang dilakukan pada populasi yang cukup besar, namun data yang dipelajari adalah data dari sampel yang diambil dari populasi tersebut, sehingga ditemukan kejadian-kejadian relatif distribusi dan hubungan-hubungan antar variabel sosiologi maupun psikologi. Penelitian ini bertujuan untuk mengetahui pengaruh citra rumah sakit dan kualitas pelayanan terhadap loyalitas konsumen melalui kepuasan konsumen. 


\section{Sumber Data}

a. Data Primer

Data primer dalam penelitian ini adalah data tentang profil sosial dan identifikasi responden, berisi data responden dalam bentuk kuesioner yang berhubungan dengan identitas responden dan keadaan sosial seperti: usia, jenis kelamin, pendidikan terakhir, dan hasil jawaban dari pertanyaan yang peneliti ajukan.

b. Data Sekunder

Data sekunder dalam penelitian ini meliputi data dari RSU Kardinah Tegal Tegal tentang profil dan pasien, buku dan referensi pendukung lainnya.

Berikut adalah tabel ringkasan beberapa fit index:

Tabel 4 Goodness of Fit Index

\begin{tabular}{|c|c|}
\hline Goodness of fit index & Nilai batas \\
\hline Chi square & $<\mathrm{X}^{2} ; \alpha=0,05$ \\
\hline Significant probability & $\geq 0,05$ \\
\hline GFI & $\geq 0,90$ \\
\hline$A G F I$ & $\geq 0,90$ \\
\hline CFI & $\geq 0,95$ \\
\hline TLI & $\geq 0,95$ \\
\hline RMR & $\leq 0,05$ \\
\hline RMSEA & $\leq 0,08$ \\
\hline
\end{tabular}

1) Uji Reliabilitas dan Varience Extract

a) Uji reliabilitas, di mana reliabilitas yang diterima adalah $\geq$ 0,70. Uji reliabilitas dalam SEM dapat diperoleh melalui rumus :

Construk reliability $=$

$$
\frac{(\Sigma \text { Std.Loading })^{2}}{(\Sigma \text { Std.Loading })^{2}+\epsilon_{\mathrm{j}}}
$$

Keterangan:

Standard Loading diperoleh dari standardized loading untuk tiaptiap indikator yang didapat dari hasil perhitungan komputer $\epsilon . \mathrm{j}$ adalah measurement error dari tiap-tiap indikator

b) Variance Extract, di mana nilai yang dapat diterima adalah $\geq$ 0,50. Rumus yang digunakan adalah sebagai berikut :

Variance Extract $=\frac{\sum \text { Std.Loading }^{2}}{\sum \text { Std.Loading }^{2}+\epsilon_{\mathrm{j}}}$

Keterangan:

Standard Loading diperoleh dari standardized loading untuk tiap- tiap indikator yang didapat dari hasil perhitungan komputer $\in . \mathrm{j}$ adalah measurement error dari tiap-tiap indikator (1Std. Loading) ${ }^{2}$

c) Intrepretasi dan modifikasi model Langkah terakhir adalah menginterpretasikan model dan memodifikasikan model bagi model-model yang tidak memenuhi syarat pengujian yang dilakukan. Cut-off value sebesar 2,58 dapat digunakan untuk menilai signifikansi tidaknya residual yang dihasilkan oleh model. Nilai residual yang lebih besar atau sama dengan $\pm 2,58$ diinterpretasikan sebagai signifikan secara statistik pada tingkat 5\%

\section{HASIL PENELITIAN}

Penelitian ini bertujuan untuk mengetahui pengaruh citra dan kualitas 
pelayanan terhadap kepuasan konsumen dan loyalitas pasienpada RSU Kardinah Tegal. Data penelitian diperoleh dari hasil pengisian kuesioner kepada sebanyak 146 responden yang seluruhnya merupakan seluruh pasien RSU Kardinah Tegal yang telah melakukan pelayanan medis sebanyak 5 kali.

Data hasil penelitian selanjutnya dianalisis secara deskriptif dan kuantitatif untuk mendapatkan gambaran citra dan kualitas pelayanan rumah sakit serta kepuasan dan loyalitas pasien terhadap RSU Kardinah Tegal. Analisis deskriptif dilakukan dengan melihat nilai mean dan median, sedangkan analisis kuantitatif dilakukan dengan menggunakan teknik analisis SEM dengan bantuan program AMOS versi 22.

Tabel 6. Analisis Deskriptif Variabel Citra

\begin{tabular}{|c|c|c|c|c|c|c|c|c|c|c|c|c|c|}
\hline \multirow{2}{*}{ Indikator } & \multicolumn{5}{|c|}{ Jumlah (n) } & \multicolumn{5}{|c|}{ Persentase (\%) } & \multirow{2}{*}{ mean } & \multirow{2}{*}{ std dev } & \multirow{2}{*}{ median } \\
\hline & STS & $\mathrm{TS}$ & $\mathrm{N}$ & $S$ & $\mathrm{SS}$ & STS & $\mathrm{TS}$ & $\mathrm{N}$ & $\mathrm{S}$ & $\mathrm{SS}$ & & & \\
\hline Personality & 1 & 2 & 4 & 79 & 60 & 0.68 & 1.37 & 2.74 & 54.11 & 41.10 & 4.34 & 0.67 & 4.00 \\
\hline Reputation & 0 & 3 & 5 & 104 & 34 & 0.00 & 2.05 & 3.42 & 71.23 & 23.29 & 4.16 & 0.57 & 4.00 \\
\hline Values & 0 & 3 & 2 & 79 & 62 & 0.00 & 2.05 & 1.37 & 54.11 & 42.47 & 4.37 & 0.62 & 4.00 \\
\hline $\begin{array}{l}\text { Corporate } \\
\text { Identity }\end{array}$ & 3 & 0 & 3 & 120 & 20 & 2.05 & 0.00 & 2.05 & 82.19 & 13.70 & 4.05 & 0.58 & 4.00 \\
\hline
\end{tabular}

Berdasarkan tabel di atas, dapat dilihat nilai rata-rata tertinggi variabel citra berada pada indikator values dengan rata-rata sebesar 4,37 dan standar deviasi sebesar 0,62 , sedangkan nilai rata-rata terendah berada pada variabel corporete identity. Dalam pertanyaan terbuka yang terdapat dalam kuesioner, $82 \%$ pasien menjawab bahwa citra RSU Kardinah Tegal sudah baik dan sisanya $18 \%$ menjawab citra rumah sakit tidak baik. Sebagian besar pasien menilai citra RSU Kardinah Tegal sudah baik karena RSU Kardinah Tegal memiliki reputasi yang baik dan sudah terstandarisasi tipe B yang memiliki jumlah dan kualitas karyawan serta pelayanan yang baik, sehingga mudah diingat dalam benak masyarakat. Hal ini menunjukkan bahwa pada dasarnya citraRSU Kardinah Tegal telah dipahami dengan baik oleh lingkungan di luar rumah sakit, namun segala sesuatu yang terkait dengan personality, reputation, values dan corporate identity harus lebih ditingkatkan lagi agar citra rumah sakit menjadi lebih baik.

Tabel 7. Analisis Deskriptif Kualitas Pelayanan

\begin{tabular}{|c|c|c|c|c|c|c|c|c|c|c|c|c|c|}
\hline \multirow{2}{*}{ Indikator } & \multicolumn{5}{|c|}{ Jumlah (n) } & \multicolumn{5}{|c|}{ Persentase $(\%)$} & \multirow{2}{*}{ Mean } & \multirow{2}{*}{ std dev } & \multirow{2}{*}{ median } \\
\hline & STS & TS & $\mathrm{N}$ & $\mathrm{S}$ & SS & STS & $\mathrm{TS}$ & $\mathrm{N}$ & $S$ & SS & & & \\
\hline Tangible & 1 & 0 & 9 & 110 & 26 & 0.68 & 0.00 & 6.16 & 75.34 & 17.81 & 4.10 & 0.54 & 4.00 \\
\hline Reliabel & 1 & 0 & 8 & 100 & 37 & 0.68 & 0.00 & 5.48 & 68.49 & 25.34 & 4.18 & 0.58 & 4.00 \\
\hline Responsiveness & 1 & 2 & 15 & 92 & 36 & 0.68 & 1.37 & 10.27 & 63.01 & 24.66 & 4.10 & 0.68 & 4.00 \\
\hline Assurance & 1 & 0 & 15 & 95 & 35 & 0.68 & 0.00 & 10.27 & 65.07 & 23.97 & 4.12 & 0.63 & 4.00 \\
\hline Emphaty & 0 & 0 & 8 & 94 & 44 & 0.00 & 0.00 & 5.48 & 64.38 & 30.14 & 4.25 & 0.55 & 4.00 \\
\hline
\end{tabular}

Berdasarkan tabel di atas, dapat dilihat nilai rata-rata tertinggi berada pada indikator emphaty, sedangkan nilai rata- rata terendah berada pada indikator tangible dan responsivenness. Hal ini menunjukkan bahwa pada dasarnya RSU 
Kardinah Tegal telah memiliki emphaty yang tinggi terhadap konsumen, namun dalam hal daya tarif fasilitas fisik dan responsiveness petugas masih perlu ditingkatkan. Dalam pertanyaan terbuka yang terdapat dalam kuesioner, $88 \%$ pasien menjawab bahwa kualitas pelayanan RSU Kardinah Tegal sudah baik dan sisanya $12 \%$ menjawab citra rumah sakit tidak baik. Sebagian besar pasien menilai kualitas pelayanan RSU Kardinah Tegal sudah baik karena RSU Kardinah Tegal memiliki fasilitas yang memadai dan karyawan RSU Kardinah mampu memahami permasalahan dan merespon kebutuhan pasien dengan cepatHal ini menunjukan walaupun sebagian besar pasien menganggap kualitas pelayanan sudah baik, namun kualitas pelayanan harus ditingkatkan agar pasien tidak berpindah ke rumah sakit lain diantara dengan meningkatkan kualitas pelayanan, meningkatkan fasilitas yang sudah ada, memahami permasalahan pasien mampu memberikan rasa aman dan kepercayaan kepada pasien.

Tabel 8. Analisis Deskripsi Kepuasan Pasien

\begin{tabular}{|c|c|c|c|c|c|c|c|c|c|c|c|c|c|}
\hline \multirow{2}{*}{ Indikator } & \multicolumn{5}{|c|}{ Jumlah (n) } & \multicolumn{5}{|c|}{ Persentase $(\%)$} & \multirow{2}{*}{ mean } & \multirow{2}{*}{ std dev } & \multirow{2}{*}{ median } \\
\hline & STS & TS & $\mathrm{N}$ & $\mathrm{S}$ & SS & STS & $\mathrm{TS}$ & $\mathrm{N}$ & $\mathrm{S}$ & SS & & & \\
\hline Kesesuaian_harapan & 0 & 1 & 2 & 91 & 52 & 0.00 & 0.68 & 1.37 & 62.33 & 35.62 & 4.33 & 0.5396 & 4.00 \\
\hline Persepsi_kinerja & 1 & 0 & 2 & 100 & 43 & 0.68 & 0.00 & 1.37 & 68.49 & 29.45 & 4.26 & 0.55155 & 4.00 \\
\hline Penilaian_Konsumen & 2 & 1 & 2 & 84 & 57 & 1.37 & 0.68 & 1.37 & 57.53 & 39.04 & 4.32 & 0.674 & 4.00 \\
\hline
\end{tabular}

Berdasarkan tabel di atas, tingkat kepuasan pasien RSU Kardinah Tegal pada dasarnya telah tinggi, rata-rata tertinggi kepuasan konsumen berada pada indikator kesesuaian harapan sedangkan rata-rata terendah pada indikator persepsi kerja, hal ini menunjukkan bahwa pada dasarnya jasa yang ditawarkan RSU Kardinah Tegal telah sesuai dengan harapan para konsumen, namun dalam hal hasil atau kinerja pelayanan yang diterima masih perlu ditingkatkan. Dalam pertanyaan terbuka yang terdapat dalam kuesioner, $85 \%$ pasien menjawab sudah merasa puas dan sisanya $15 \%$ menjawab tidak merasa puas. Sebagian besar pasien menilai sudah merasa puas berobat di RSU Kardinah Tegal, hal ini dikarenakan RSU Kardinah Tegal telah memberikan kenyamanan kepada pasien ketika berobat dan layanan yang ditawarkan RSU Kardinah sudah sesuai dengan harapan pasienHal ini menunjukan bahwa harapan pasien, persepsi kinerja dan penilaian pasien perlu untuk diwujudkan dengan sebaik mungkin oleh pihak RSU Kardinah Tegal agar pasien senantiasa puas jika berobat di RSU Kardinah Tegal.

Tabel 9. Analisis Deskriptif Loyalitas Pasien

\begin{tabular}{|c|c|c|c|c|c|c|c|c|c|c|c|c|c|}
\hline \multirow{2}{*}{ Indikator } & \multicolumn{5}{|c|}{ Jumlah (n) } & \multicolumn{5}{|c|}{ Persentase $(\%)$} & \multirow{2}{*}{ mean } & \multirow{2}{*}{ std dev } & \multirow{2}{*}{ median } \\
\hline & STS & TS & $\mathrm{N}$ & $S$ & SS & STS & TS & $\mathrm{N}$ & $S$ & SS & & & \\
\hline Trust & 2 & 1 & 2 & 84 & 57 & 1.37 & 0.68 & 1.37 & 57.53 & 39.04 & 4.32 & 0.67 & 4.00 \\
\hline $\begin{array}{l}\text { Emotion } \\
\text { commitment }\end{array}$ & 0 & 4 & 12 & 85 & 45 & 0.00 & 2.74 & 8.22 & 58.22 & 30.82 & 4.17 & 0.69 & 4.00 \\
\hline Switchingcost & 2 & 1 & 10 & 100 & 33 & 1.37 & 0.68 & 6.85 & 68.49 & 22.60 & 4.10 & 0.66 & 4.00 \\
\hline WOM & 1 & 2 & 3 & 112 & 28 & 0.68 & 1.37 & 2.05 & 76.71 & 19.18 & 4.12 & 0.56 & 4.00 \\
\hline Cooperation & 0 & 5 & 14 & 88 & 39 & 0.00 & 3.42 & 9.59 & 60.27 & 26.71 & 4.10 & 0.70 & 4.00 \\
\hline
\end{tabular}


Berdasarkan tabel di atas, dapat dilihat pada dasarnya loyalitas pasien cenderung tinggi. Nilai rata-rata tertinggi diperoleh oleh indikator trust sedangkan nilai rata-rata terendah diperoleh oleh indikator switchingcost dan cooperation. Dalam pertanyaan terbuka yang terdapat dalam kuesioner, $88 \%$ pasien menjawab sudah loyal terhadap RSU Kardinah Tegal dan sisanya $12 \%$ menjawab tidak loyal. Sebagian besar pasien menilai sudah merasa loyal berobat di RSU Kardinah Tegal, hal ini dikarenakan RSU Kardinah Tegal selalu memberikan kepuasan dan mewujudkan apa yang diinginkan oleh pasien. Hal ini menunjukkan bahwa loyalitas konsumen pada dasarnya telah baik namun masih perlu adanya peningkatan dalam hal kepercayaan pasien terhadap RSU
Kardinah Tegal masih perlu ditingkatkan sehingga nantinya pasien akan merekomendasikan kepada orang lain untuk berobat ke RSU Kardinah

\section{a. Convergent Validity}

Untuk mengukur validitas konstruk dapat dilihat dari nilai faktor loadingnya. Syarat utama yang harus dipenuhi adalah loading factor harus signifikan dan standarized loading estimateharus sama dengan 0,5 atau lebih, adapun idealnya standarized loading estimate indikator adalah 0,70 (Ghozali; 2011:137). Berikut ini adalah nilai signifikan dan loading factor masingmasing indikator dalam mengukur konstruknya.

Tabel 10.Nilai Standarized Loading Factor (SLF) Indikator terhadap Konstruknya

Regression Weights: (Group number 1 - Default model)

\begin{tabular}{|c|c|c|c|c|c|c|c|}
\hline & & & Estimate & S.E. & C.R. & $\mathrm{P}$ & Label \\
\hline $\mathrm{C} 4$ & $\begin{array}{c}<-- \\
\end{array}$ & CITRA & 1,000 & & & & \\
\hline $\mathrm{C} 3$ & $<--$ & CITRA & 1,160 & ,138 & 8,426 & $* * *$ & par_1 \\
\hline $\mathrm{C} 2$ & $<--$ & CITRA & ,992 & ,126 & 7,847 & $* * *$ & par_2 \\
\hline $\mathrm{C} 1$ & $<--$ & CITRA & 1,270 & 149 & 8,508 & $* * *$ & par_3 \\
\hline KP5 & $<--$ & KUALITAS_PELAYANAN & 1,000 & & & & \\
\hline KP4 & $<--$ & KUALITAS_PELAYANAN & 1,271 & ,225 & 5,648 & $* * *$ & par_4 \\
\hline KP3 & $<--$ & KUALITAS_PELAYANAN & 1,088 & 200 & 5,452 & $* * *$ & par_5 \\
\hline KP2 & $<--$ & KUALITAS_PELAYANAN & ,965 & ,187 & 5,172 & $* * *$ & par_6 \\
\hline KP1 & $<--$ & KUALITAS_PELAYANAN & 1,111 & 214 & 5,187 & *** & par_7 \\
\hline KK3 & $<--$ & KEPUASAN_KONSUMEN & 1,000 & & & & \\
\hline KK2 & $<--$ & KEPUASAN_KONSUMEN & ,686 & 264 & 2,599 & ,009 & par_8 \\
\hline KK1 & $<--$ & KEPUASAN_KONSUMEN & ,544 & 240 & 2,264 & ,024 & par_9 \\
\hline L1 & $<--$ & LOYALITAS & 1,000 & & & & \\
\hline L2 & $<--$ & LOYALITAS & ,924 &, 128 & 7,226 & $* * *$ & par_10 \\
\hline L3 & $<--$ & LOYALITAS & ,990 &, 122 & 8,109 & $* * *$ & par_11 \\
\hline L4 & $<--$ & LOYALITAS &, 846 & ,099 & 8,518 & $* * *$ & par_12 \\
\hline L5 & $<--$ & LOYALITAS &, 749 & ,127 & 5,908 & $* * *$ & par_13 \\
\hline
\end{tabular}


Hasil Perhitungan Construct Reliability

\begin{tabular}{|c|c|c|c|c|c|c|c|}
\hline Konstruk & Indikator & $\Lambda$ & $\lambda^{2}$ & $1-\lambda 2$ & $\sum 1-\lambda^{2}$ & $\sum \lambda$ & CR \\
\hline \multirow{4}{*}{ Citra } & Personality & 0.696 & 0.484 & 0.516 & \multirow{4}{*}{1.842} & \multirow{4}{*}{2.935} & \multirow{4}{*}{0,778} \\
\hline & Reputation & 0.759 & 0.576 & 0.424 & & & \\
\hline & Values & 0.706 & 0.498 & 0.502 & & & \\
\hline & Corporate_Identity & 0.774 & 0.599 & 0.401 & & & \\
\hline \multirow{5}{*}{$\begin{array}{l}\text { Kualitas } \\
\text { Pelayanan }\end{array}$} & Tangible & 0.538 & 0.289 & 0.711 & \multirow{5}{*}{3.150} & \multirow{5}{*}{3.036} & \multirow{5}{*}{0,771} \\
\hline & Reliabel & 0.633 & 0.401 & 0.599 & & & \\
\hline & Responsiveness & 0.63 & 0.397 & 0.603 & & & \\
\hline & Assurance & 0.601 & 0.361 & 0.639 & & & \\
\hline & Emphaty & 0.634 & 0.402 & 0.598 & & & \\
\hline \multirow{3}{*}{$\begin{array}{l}\text { Kepuasan } \\
\text { Pasien }\end{array}$} & Kesesuaian_harapan & 0.586 & 0.343 & 0.657 & \multirow{3}{*}{2.058} & \multirow{3}{*}{1.68} & \multirow{3}{*}{0,881} \\
\hline & Persepsi_kinerja & 0.545 & 0.297 & 0.703 & & & \\
\hline & Penilaian_Konsumen & 0.549 & 0.301 & 0.699 & & & \\
\hline \multirow{5}{*}{ Loyalitas } & Trust & 0.733 & 0.537 & 0.463 & \multirow{5}{*}{1.733} & \multirow{5}{*}{3.406} & \multirow{5}{*}{0,848} \\
\hline & Eotion_commitment & 0.663 & 0.440 & 0.560 & & & \\
\hline & Switchingcost & 0.739 & 0.546 & 0.454 & & & \\
\hline & WOM & 0.744 & 0.554 & 0.446 & & & \\
\hline & Cooperation & 0.527 & 0.278 & 0.722 & & & \\
\hline
\end{tabular}

Berdasarkan tabel di atas, dapat dilihat nilai CR seluruh konstruk > 0,70 yang

menunjukkan bahwa seluruh konstruk memiliki reliabilitas yang baik.

\section{Hasil Analisis SEM}

Regression Weights: (Group number 1 - Default model)

\begin{tabular}{|ccc|ccccc|}
\hline & & Estimate & S.E. & C.R. & P & Label \\
\hline KEPUASAN & $<---$ & CITRA & 2,229 & 1,467 & 4,519 &, 016 & par_14 \\
KEPUASAN & $<---$ & KUALITAS_PELAYANAN & 2,358 & 1,808 & 3,304 &, 002 & par_16 \\
LOYALITAS & $<---$ & KEPUASAN_KONSUMEN & 1,733 & 3,915 & 2,187 &, 036 & par_15 \\
LOYALITAS & $<---$ & KUALITAS_PELAYANAN & 1,989 & 10,828 & 1,984 &, 015 & par_17 \\
LOYALITAS & $<---$ & CITRA & 2,948 & 10,043 & 3,294 &, 009 & par_18 \\
\hline
\end{tabular}

Berdasarkan tabel di atas, diperoleh beberapa kesimpulan sebagai berikut :

1) Nilai signfikan pengaruh variabel citra terhadap kepuasan konsumen adalah sebesar $0,016<0,05$ dan nilai standard estimate bertanda positif menunjukkan bahwa variabel citra berpengaruh positif dan signifikan terhadap variabel kepuasan pasien. Semakin tinggi citra RSU Kardinah Tegal maka semakin tinggi kepuasan pasien RSU Kardinah Tegal, begitu sebaliknya.

2) Nilai signfikan pengaruh variabel kualitas pelayanan terhadap kepuasan pasien adalah sebesar 0,002 $<0,05$ dan standard estimate bertanda positif menunjukkan bahwa kualitas pelayanan berpengaruh positif dan signifikan terhadap kepuasan pasien. Semakin tinggi kualitas pelayanan 
maka semakin tinggi kepuasan pasien, begitu sebaliknya.

3) Nilai signfikan pengaruh variabel citra terhadap loyalitas pasien adalah sebesar $0,036<0,05$ dan nilai standard estimate bertanda positif menunjukkan bahwa variabel citra berpengaruh positif dan signifikan terhadap variabel loyalitas pasien. Semakin tinggi citra RSU Kardinah Tegal maka semakin tinggi loyalitas pasien, begitu sebaliknya.

4) Nilai signfikan pengaruh variabel kualitas pelayanan terhadap loyalitas pasien adalah sebesar $0,015<0,05$ menunjukkan bahwa variabel kualitas pelayanan berpengaruh signifikan terhadap variabel loyalitas pasien. Semakin tinggi kualitas pelayanan maka semakin tinggi loyalitas pasien, begitu sebaliknya.

5) Nilai signfikan pengaruh variabel kepuasan pasien terhadap loyalitas adalah sebesar $0,009<0,05$ menunjukkan bahwa variabel kepuasan pasien berpengaruh signifikan terhadap variabel loyalitas. Semakin tinggi kepuasan pasien maka semakin tinggi loyalitas pasien, begitu sebaliknya.

\section{Hasil Pengujian Hipotesis}

\begin{tabular}{|l|l|l|}
\hline No & Hipotesis & Hasil \\
\hline 1 & $\begin{array}{l}\text { Citra RS berpengaruh positif dan signifikan terhadap variabel } \\
\text { Kepuasan pasien }\end{array}$ & diterima \\
\hline 2 & $\begin{array}{l}\text { Kualitas Pasien berpengaruh positif dan signifikan terhadap } \\
\text { variabel Kepuasan pasien }\end{array}$ & diterima \\
\hline 3 & $\begin{array}{l}\text { Citra berpengaruh positif dan signifikan terhadap variabel } \\
\text { loyalitas pasien }\end{array}$ & diterima \\
\hline 4 & $\begin{array}{l}\text { Kualitas Pasien berpengaruh positif dan signifikan terhadap } \\
\text { variabel loyalitas pasien }\end{array}$ & diterima \\
\hline 5 & $\begin{array}{l}\text { Kepuasan pasien berpengaruh positif dan signifikan terhadap } \\
\text { loyalitas pasien }\end{array}$ & diterima \\
\hline $6 a$ & $\begin{array}{l}\text { Kepuasan Pasien mampu memediasi pengaruh citra RS } \\
\text { dankualitas pelayanan terhadap loyalitas pasien }\end{array}$ & diterima \\
\hline $6 b$ & $\begin{array}{l}\text { Kepuasan Pasien mampu memediasi pengaruh kualitas } \\
\text { pelayanan dan terhadap loyalitas pasien }\end{array}$ & ditolak \\
\hline
\end{tabular}

\section{E. SIMPULAN DAN SARAN}

Kesimpulan yang diperoleh dari hasil penelitian ini adalah sebagai berikut :

1. Citra RSU Kardinah Tegal berpengaruh positif terhadap kepuasan pasien. Semakin tinggi citra RSU Kardinah Tegal maka kepuasan pasien semakin tinggi, begitu sebaliknya.

2. Kualitas pelayanan RSU Kardinah Tegal berpengaruh positif terhadap kepuasan pasien. Semakin tinggi kualitas pelayanan RSU Kardinah Tegal maka kepuasan pasien semakin tinggi begitu sebaliknya.

3. Citra RSU Kardinah Tegal berpengaruh positif terhadap loyalitas pasien. Semakin tinggi citra RSU Kardinah Tegal maka loyalitas pasien semakin tinggi, begitu sebaliknya.

4. Kualitas pelayanan RSU Kardinah Tegal berpengaruh positif terhadap 
loyalitas pasien. Semakin tinggi kualitas pelayanan RSU Kardinah Tegal maka loyalitas pasien semakin tinggi, begitu sebaliknya.

5. Kepuasan pasien berpengaruh positif terhadap loyalitas pasien. Semakin tinggi kepuasan pasien maka loyalitas pasien semakin tinggi, begitu sebaliknya.

6. Kepuasan pasien dapat memediasi pengaruh citra RSU Kardinah Tegal terhadap loyalitas pasien namun kepuasan pasien tidak mampu memediasi pengaruh kualitas pelayanan terhadap loyalitas pasien.

\section{Saran}

Beberapa saran yang dapat disampaikan dari hasil penelitia ini adalah sebagai berikut:

1. Bagi pihak RSU Kardinah Tegal

a. Pihak manajemen RSU Kardinah harus meningkatkan citra rumah sakit dengan cara meningkatkan promosi kepada masyarakat aga
RSU Kardinah lebih dikenal dan diingat oleh masyarakat. Senantiasa meningkatkan reputasi RSU Kardinah agar lebih baik serta meningkatkan standarisasi agar menjadi rumah sakit tipe A.

b. Pihak manajemen RSU Kardinah harus meningkatkan kualitas pelayanan dengan cara meningkatkan fasilitas yang tersedia di RSU Kardinah, karyawan harus selalu mengetahui permasalahan yang dihadapi pasien dan merespon permintaan pasien dengan cepat. RSU Kardinah harus meningkatkan layanan yang akurat dan mampu memberikan rasa aman serta kepercayaan kepada pasien

2. Bagi penelitian selanjutnya

Peneliti dapat menambah variabel eksogen selain citra dan kualitas pelayanan yang dapat berpengaruh terhadap kepuasan pelangan dan loyalitas.

\section{DAFTAR PUSTAKA}

Alexander Da Silva. (2003). Customer Loyalty and Complex Service; The Impact of Corporate Image on Quality, Customer Satisfaction and Loyalty for Coustomers with Varrying Degrees of Service Expertise. Int J. Serv. Ind. Management.

Anwar, Prabu. (2002). Manajemen Sumber Daya Manusia. Bandung : PT. Remaja Rosda Karya

Ariyani, Dwi dan Rosinta, Febrina. (2010). Pengaruh Kualitas Layanan terhadap Kepuasan Konsumen dalam Membentuk Loyalitas Konsumen. Jurnal Ilmu Administrasi dan Organisasi. Volume 17, Nomor 2 hlm. 114-126

Arzena, Meigy. (2013) Pengaruh Kepuasan atas Kualitas Pelayanan dan Kepercayaan Terhadap Loyalitas Nasabah PT. Bank Mandiri Cabang muaro Padang. Jurnal Manajemen Vol 2, No 02.

Bayhaqi, Yuzza. (2006) Analisis Pengaruh Kualitas Layanan dan Keunggulan Produk terhadap Kepuasan Konsumen dan Dampaknya pada Minat Membeli Ulang. Universitas Diponegoro: Tesis 
Caruana, Albert; Arthur H. Money dan Pierre R. Berthon (2012), "Service Quality and Satisfaction - The moderating role of value", European Jurnal of Marketing, Vol 34(11/12), p:1338-1352

Consuegra. 2007. "An Integrated Model Of Price,Satisfaction and Loyalty: An Empirical Analysis In The Service Sector." Emerald Group Publishing Limited. Journal of Product and Brand Management, Volume 16,Number 7, 2007 , pp. 459-468(10).

Deli Darlina, (2015). Pengaruh Citra Perusahaan dan Kualitas Pelayanan Terhadap Loyalitas Konsumen Pada Jasa Perhotelan. Universitas Riau: Tesis

Engel, J.F, Blackwell, Rd, and Miniard, DW. (2005). Perilaku Konsumen. Jilid 1. (Boediono, Terjemahan). Jakarta: Bina Rupa Akasara.

Griffin, J. (2013). Customer Loyalty: Menumbuhkan Dan Mempertahankan Kesetiaan Konsumen (Terjemahan). Jakarta: Erlangga.

(2010). Customer Loyalty: Menumbuhkan Dan Mempertahankan Kesetiaan Konsumen (Terjemahan). Jakarta: Erlangga.

Ghozali, Imam. (2011). Aplikai Analisis Multivarite dengan SPSS. Cetakan Keempat. Semarang: Badan Penerbit Universitas Diponegoro.

Goodwin, Victor. (2009). Manajemen Pemasaran Jasa. Jakarta: PT Salemba Empat.

Gremler, D.D. dan Stephen W. Brown. (2007). Servive Loyalty: Its Nature, Important, and Implications. New York: Internasional Service Qualiy Asosiation Inc.

Harrison, Shirley. 2007. Public Relations : An Introduction, London, Thomson.

Hellier, Philip K., et al.(2012), “Customer Repurchase Intention”, European Journal of Marketing.

Hidajahningtyas, Nurullah. (2013). Pengaruh Citra Poliklinik Eksekutif Rumah sakit Daerah dr. Soebandi Kabupaten Jember. Jurnal Vol XII No. 1/2013.

Hidayat, Taufik. (2009). Manajemen Pemasaran. Bandung: ALFABETA.

Hoeffler, S. dan Keller, K.K. (2003), "The marketing advantages of strong brands", Brand Management, Vol. 10 No. 6, pp. 421-45.

Istijanto. (2005). Aplikasi Praktis: Riset Pemasaran. PT. Gramedia Pustaka Utama. Jakarta

Kotler, Philip. (2007). Manajemen Pemasaran,Edisi Kedua belas, Jilit 2 Edisi Bahasa Indonesia. Jakarta: Indeks.

Laksana, Fajar. (2008). Manajemen Pemasaran; Pendekatan Praktis. Yogyakarta: Graha Ilmu.

Lina, Prahastuti. (2011) “Analisis Pengaruh Kualitas Layanan dan Kualitas Produk Terhadap Kepuasan Konsumen Untuk Meningkatkan Loyalitas Konsumen Indosat." Fakultas Ekonomi Universitas Diponegoro Semarang.

Margita (2016) "Pengaruh citra rumah sakit dan Kualitas Pelayanan Terhadap Loyalitas melalui Kepuasan Konsumen: (Studi Pada RS Wonogiri)" Jurnal Manajemen Vol II. 
Marilees,B.\&Fry ,M. 2012.Corporate Branding: A framework for E-Retaliers. Corporate Reputation Review Vol. 5.

Oliver, R.L (2009). "Whence Consumer Loyalty",Journal of Marketin., Volume 63 Special Issue, pp. 33-44

Porter,S.S., Claycomb,C. (2007). The Influence of Brand Recognation on Retail Store Image. Journal of Prod. Brand Management.

Ratih Hurriyati, (2005), Marketing Research. USA, New Jersey. Prentice Hall, Pearson Education Inc.

Retno, Lestari (2014), Analisis Pengaruh Citra Toko Terhadap Kepuasan Konsumen Carefour, Jurnal Ilmiah STIE MDP.

Saputra Falla, (2013) Kualitas Layanan, Citra dan pengaruhnya terhadap Loyalitas melalui Kepuasan Konsumen: (Studi kasus pada Bank BNI 46 Sentra Kredit Surabaya) Jurnal Manajemen Vol II.

Selnes, Fred (2003), "An Examination of the Effect of Product Performance on Board Reputation, Satisfaction and Loyalty."European Journal of Marketing

Suliyanto. 2011. Ekonomi Terapan: Teori \& Aplikasi dengan SPSS. Yogyakarta: Penerbit ANDI

Sutisna. (2001). Perilaku Konsumen dan Komunikasi Pemasaran. Edisi Kedua. Jilid Pertama. Bandung: Remaja Posdaya.

Syamsiah, N. (2009). Analisis Faktor-Faktor yang Mempengaruhi Nilai yang Dirasakan Konsumen untuk Menciptakan Kepuasan Konsumen di RSUP Dokter Kariadi Semarang. Tesis: Universitas Diponegoro.

Tjiptono, F. (2001). Manajemen Jasa. Edisi Kedua. Yogyakarta: Andi Offiset. . (2004). Prinsip-prinsip Total Quality Service. Yogyakarta: Andi. . (2008). Pemasaran Jasa. Malang: Bayumedia Publishing.

Wijayanti Ari, 2008. Strategi Meningkatkan Loyalitas Melalui Kepuasan Konsumen (Studi Kasus : Produk Kartu Selular PraBayar Mentari - Indosat Wilayah Semarang). Jurnal. Manajemen Universitas Dipanegoro.

Widiyawati, N. (2013). "Pengaruh Kualitas Layanan Terhadap Loyalitas Konsumen Di Supermarket Papaya Darmo Surabaya”. Universitas Pembangunan Nasional Jawa Timur: Tesis.

$\mathrm{Wu}, \mathrm{C}$ (2011). "The Impact of Hospital Brand Image on servive Quality, Patient Satisfaction and Loyalty" Journal of Business Management Vol. 5(12), pp. 48734882.

Fatmawati, Ika. 2004. Manajemen Pemasaran Jasa. Jakarta: Penerbit Salemba Empat

Yamin, Sofyan dkk. 2011. Regresi dan Korelasi dalam Genggaman Anda. Jakarta: Penerbit Salemba Empat

Zeithmal, VA, Barry and Parasuraman. (2000). Delivering Quality Service : Balancing Customer Perseptions and Expectations. Collier Macmilllan Publishers.

Zeithaml,Valarie. Bitner. Mary Jo. (2006). Service Marketing. Internatinonal Edition. The Mcgraw-Hill. 